\title{
Mechanochemically aminated multilayer graphene for carbon/polypropylene graft polymers and nanocomposites
}

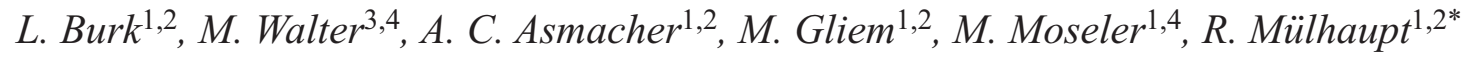 \\ ${ }^{1}$ Freiburg Materials Research Center (FMF), Stefan-Meier-Straße 21, D-79104 Freiburg, Germany \\ ${ }^{2}$ Institute for Macromolecular Chemistry of the Albert-Ludwigs-University Freiburg, Stefan-Meier-Straße 31, \\ D-79104 Freiburg, Germany \\ ${ }^{3}$ Freiburg Center for Interactive Materials and Bioinspired Technologies (FIT), Georges-Köhler-Allee 105, \\ D-79110 Freiburg, Germany \\ ${ }^{4}$ Fraunhofer IWM, Wöhlerstraße 11, D-79108 Freiburg, Germany
}

Received 10 August 2018; accepted in revised form 7 November 2018

\begin{abstract}
The two-stage mechanochemical amination of graphite by dry ball milling of graphite in a planetary ball mill under Ar followed by $\mathrm{NH}_{3}$ yields aminated multilayer graphene (AMFG) as intermediates for carbon/polymer hybrids and nanocomposites. Opposite to efficient edge-selective graphene functionalization under $\mathrm{Ar}, \mathrm{CO}_{2}$ and $\mathrm{N}_{2}$ pressure, the onestage ball milling under $\mathrm{NH}_{3}$ pressure affords rather low $\mathrm{N}$ content $(<0.5 \mathrm{wt} \%)$ and fails to reduce the graphite platelet size. According to DFT (Density Functional Theory) calculations $\mathrm{NH}_{3}$ exhibits low mobility between graphene layers and forms weak bonds to carbon which impair breakage of carbon bonds. In the two-stage ball-milling of graphite under Ar affords reactive carbon nanoparticles which react with $\mathrm{NH}_{3}$ in the second stage. With increasing milling duration of the second stage the nitrogen content increases to $3.2 \mathrm{wt} \%$. As verified by XPS (X-ray photoelectron spectroscopy) measurements primary amine groups are formed which couple with various dicarboxylic anhydride groups including maleated PP to produce imidefunctionalized graphene. This is of interest to produce compatibilizers and dispersing agents for carbon/PP nanocomposites exhibiting improved mechanical properties. Two-stage mechanochemistry holds promise for carbon nanoparticle functionalization well beyond amination.
\end{abstract}

Keywords: nanocomposites, carbon, mechanochemistry, graphene, amination

\section{Introduction}

Among carbon allotropes, graphene as a 2D carbon polymer consists of single layer of honeycomb-like arranged $\mathrm{sp}^{2}$-hybridized carbon atoms and is outstanding with respect to its unique combination of exceptionally high Young's Modulus (1 TPa), barrier resistance to gas and fluid permeation, large specific surface area $\left(2600 \mathrm{~m}^{2} \cdot \mathrm{g}^{-1}\right)$, high electrical $\left(6000 \mathrm{~S} \cdot \mathrm{cm}^{-1}\right)$ and thermal conductivity $\left(5000 \mathrm{~W} \cdot \mathrm{m}^{-1} \cdot \mathrm{K}^{-1}\right)[1-8]$. Aiming to transfer graphene-like property profiles to $2 \mathrm{D}$ carbon/polymer compounds graphene or graphene stacks, respectively, are either covalently attached to the polymer or uniformly dispersed within the polymer matrix. Both covalent interfacial coupling and dispersion require functionalization of graphene $[9,10]$. Today several strategies are at hand for tailoring functionalized graphene (FG) [11-13]. Whereas most bottom-up processes such as chemical vapor deposition and tedious multi-step syntheses produce high purity defect-free graphene and FG at rather high cost, top-down processes are employing graphite as abundant feed stock. These approaches are more economic with respect to meeting the stringent cost requirements typical for many plastics' 
markets $[14,15]$. In the well-established top-down synthesis, known as the Hummers' process, graphite is intercalated and oxidized to form graphite oxide (GO) which is then thermally or chemically reduced yielding in single- and few-layer graphene bearing hydroxyl and carboxyl groups [16]. However, during graphite oxide reduction pores are formed within the graphene sheets thus impairing graphene properties. Moreover, this multi-step process requires handling of the explosive graphite oxide as intermediate as well as laborious purification encountering filtration problems [17]. Amination of graphene via graphite oxide can be achieved by conversion with various amines or alternatively via cycloaddition reactions of graphene through aziridine intermediates, affording amine-functionalized FG (AFG) [18-21]. During recent years, several groups are exploiting mechanochemistry for producing functionalized nanoparticles [22-27]. Mechanochemistry holds great promise for producing dispersions of graphene, multilayer graphene and mechanochemically functionalized FG (MFG) useful as functional carbon nanofillers [28]. Hernandez et al. [31] succeeded to exfoliate graphite into non-functionalized graphene dispersions using high shear mixers by exposing graphite to high shear forces in the presence of solvents with matched polarities such as $N$-methyl-pyrrolidone and $N, N$-dimethyl-formamide. Typically, such graphene dispersions have rather low graphene content well below $1 \mathrm{wt} \%$ of graphene $[29,30]$. Yet the massive addition of surfactants such as sodium dodecyl sulfate (SDS) enabled to increase graphene content without encountering massive graphene agglomeration [32]. According to Knieke et al. [32], this process afforded dispersions of single- and multilayer graphene with graphene content up to $25 \mathrm{~g} \cdot \mathrm{l}^{-1}$. An alternative solvent-and surfactant-free mechanochemical process developed by Jeon et al. [33] involves dry milling of graphite in the presence of hydrogen, carbon dioxide, sulfur trioxide, or carbon dioxide/sulfur trioxide mixtures yielding in edge-selectively functionalized MFG nanoplatelets. By varying gas atmospheres and milling conditions, they succeeded to control particle sizes, shapes and functionalization of graphene-based carbon nanoparticles. Whereas milling graphite together with dry ice gave edge-selectively carboxylated graphene nanoplatelets, the presence of nitrogen enabled the incorporation of nitrogen-containing heterocycles into the graphene structures but did not form primary amines [22, 34]. Milling graphite in the presence of ammonia was reported to produce amine-functionalized MFG (AMFG) having a nitrogen content of $4.49 \mathrm{wt} \%$ [22]. However, no further details on AMFG characterization were given. In addition to various gases also inorganic additives such as red phosphorus or sulfur were milled together with graphite in order to produce mechanochemically edge-selectively functionalized graphene nanoplatelets bearing phosphonic and sulfur groups [35, 36]. MFG was employed as filler for thermoplastics, thermosets and rubbers [22, 28, 33-37]. Opposite to single- and few-layer FG obtained by thermal reduction of graphite oxide, MFG is produced in a singlestep and solvent-free process. Since MFG comprises stacks of FG, substantially higher MFG contents are tolerated in polymer processing which improve the balance of stiffness, strength, toughness and electrical conductivity without encountering drastic viscosity increase typical for single-layer FG. Little is known with respect to exploiting either AFG or AMFG as carbon nanofillers for melt compounding of carbon/ polymer composites. Ruy and Shanmugharaj [38] grafted a long-chain alkylamine onto graphite oxide in order to produce AFG and to render hydrophilic graphene oxide organophilic and disperable in nonpolar media. In the presence of maleic-anhydridegrafted polypropylene (PP-g-MA) as compatibilizer they achieved improved AFG dispersion within the hydrophobic PP matrix accompanied by better mechanical and electrical properties. Similarly improved interfacial adhesion was reported for AFG obtained by covalent functionalization of GO with phenylenediamine and cyanuric chloride [39]. Although Jeon et al. [22] reported on mechanochemical synthesis of AMFG, to the best of our knowledge tailoring AMFG for melt compounding with PP and the formation MFG/PP nanocomposites compatibilized by grafting PP on MFG has not been reported. Herein, we examine the preparation of AMFG via dry grinding of graphite under ammonia pressure in a planetary ball mill as compared to the established MFG synthesis in the presence of argon and carbon dioxide. Density functional theory (DFT) is employed to gain better understanding how ammonia interacts and reacts with graphene during dry milling of graphite. The reaction of AMFG amine groups with 2-octen-1-yl-succinic anhydride serves as model system for IR investigation of covalent imide coupling between amine groups and pendant succinic anhydride groups of PP- $g$-MA, accounting for the formation of MFG grafted with 
$\mathrm{PP}$ as new carbon/PP hybrid material. Furthermore, AMFG is compared with non-functionalized graphite and micronized graphite $\mathrm{G}(1.5 \mu \mathrm{m})$ to elucidate the impact of both the amine functionality and carbon particle type on mechanical, thermal and morphological properties of carbon/PP composites.

\section{Experimental section}

\subsection{Materials}

All reactions and operations involving air- and moisture-sensitive substances were carried out under a dry argon atmosphere or in a glovebox (MB Braun MB 150-G-II). Argon (5.0) and ammonia (3.8) gas were supplied by AirLiquide (Kornwestheim, Germany) and Gerling Holz \& Co (Hanau, Germany), respectively, and used without further purification. Graphite (KFL, 99.5) and micronized graphite (G(1.5 $\mu \mathrm{m}), 99.9)$ were received from AMG Mining (former Kropfmühl AG, Passau, Germany). 2-Octen1-yl-succinic anhydride (97\%), isopropyl alcohol (p. a.), sulfuric acid (95-98\%) and PP-g-MA $\left(M_{\mathrm{w}} \sim\right.$ $9100 \mathrm{~g} / \mathrm{mol}, M_{\mathrm{n}} \sim 3900 \mathrm{~g} / \mathrm{mol}$, maleic anhydride = $8-10 \mathrm{wt} \%$ ) were purchased from Sigma Aldrich. The 2-octen-1-yl-succinic anhydride was further purified by distillation. Polypropylene (Moplen HP500N, isotactic, $M F R=12 \mathrm{~g} \cdot 10 \mathrm{~min}^{-1}$ at $230^{\circ} \mathrm{C}$ and $2.16 \mathrm{~kg}$ ) was obtained from LyondellBasell (Frankfurt, Germany). Irganox ${ }^{\circledR} 1010 / \operatorname{Irgafos}{ }^{\circledR} 168$ (1:1 w:w, p. a.) was purchased from BASF (CIBA, Switzerland).

\subsection{Synthesis of AMFG}

Amine-functionalized MFG (AMFG) was prepared exploiting two different mechanochemical approaches. In general, the milling chamber $(500 \mathrm{ml}$, made of $\mathrm{Y}_{0.05} \mathrm{Zr}_{0.95} \mathrm{O}_{2}$ ) and milling balls (100 piece, diameter of $10 \mathrm{~mm}$, made of $\mathrm{Y}_{0.05} \mathrm{Zr}_{0.95} \mathrm{O}_{2}$ ) were dried under reduced pressure at $40^{\circ} \mathrm{C}$, whereas Graphite $(\mathrm{KFL}$, $18.6 \mathrm{~g}$ ) was dried under reduced pressure at $60^{\circ} \mathrm{C}$. Exploiting the direct, one-stage milling process for the production of $\mathrm{AMFG}\left(\mathrm{NH}_{3}-48 \mathrm{~h}\right)$ and $\mathrm{AMFG}$ $\left(\mathrm{NH}_{3}-96 \mathrm{~h}\right)$, graphite was milled in the direct presence of gaseous ammonia. Therefore, the filled chamber was first evacuated $\left(10^{-1} \mathrm{mbar}\right)$ and then pressurized with $\mathrm{NH}_{3}$ ( 8.5 bar). Milling was performed at $250 \mathrm{rpm}$ for 48 or $96 \mathrm{~h}$ using a planetary mill PM 100 from Retsch (Haan, Germany). Exploiting the two-stage milling process for the production of $\mathrm{AMG}\left(\mathrm{Ar} / \mathrm{NH}_{3}\right)$, the chamber was first evacuated $\left(10^{-1} \mathrm{mbar}\right)$, pressurized with $\operatorname{Ar}(13 \mathrm{bar})$ and milled for $48 \mathrm{~h}$ at $250 \mathrm{rpm}$. Subsequently, the gas atmosphere was exchanged under inert conditions to $\mathrm{NH}_{3}(8.5$ bar $)$ and the milling was continued for 6-24 h at $250 \mathrm{rpm}$. Upon opening the milling chamber, the excess of gaseous $\mathrm{NH}_{3}$ was absorbed by a solution of semi concentrated sulfuric acid, whereas residues of $a b-$ sorbed $\mathrm{NH}_{3}$ on the AMFG surface were removed in vacuo $\left(10^{-2} \mathrm{mbar}\right)$ at $40^{\circ} \mathrm{C}$.

\subsection{Synthesis of imide functionalized graphene (IMFG)}

For the preparation of IMFG, AMFG(Ar/ $\left./ \mathrm{NH}_{3}\right)$ $(2.0 \mathrm{~g})$ was refluxed with an excess of freshly distilled 2-octen-1-yl-succinic anhydride (OSA) under argon atmosphere for $3 \mathrm{~d}$. IFG was filtered off and washed several times with isopropyl alcohol and then dried in a vacuum oven (20 mbar) for more than $1 \mathrm{~d}$ at $60^{\circ} \mathrm{C}$.

\subsection{Preparation of carbon/polypropylene nanocomposites}

Carbon/PP nanocomposites were prepared by melt compounding and subsequent injection molding with a filler content of 10 and $20 \mathrm{wt} \%$. The processing was done with two different matrix systems, one containing pure isotactic PP (HP500N) and the other one containing a mixture of isotactic PP (HP500N) and PP- $g$-MA in the ratio 9:1. Preferably, in order to assure a homogeneous filler distribution, the PP pellets (HP500N) were milled in a cutting mill M50/80 from Hellweg (Roetgen, Germany), whereas PP-g-MA was milled using a ultra-centrifugal mill ZM 200 from Retsch (Haan, Germany) under nitrogen cooling, followed by subsequent drying under reduced pressure at $60^{\circ} \mathrm{C}$. Prior to melt processing, both AMFG and micronized graphite were coated on the PP powder from a dispersion in acetone prepared by sonication using a Sonifier $450 \mathrm{D}$ from Branson Ultrasonics (Danbury, CT, USA) $(2 \times 5 \mathrm{~min}, 40 \%$ amplitude, ice cooling). After adding the stabilizers (0.1 wt $\%$ of Irganox ${ }^{\circledR} 1010 / \operatorname{Irgafos}{ }^{\circledR} 168$, blend ratio $1: 1)$ acetone was evaporated to yield carbon/PP blend in powder form, which was further dried under reduced pressure at $60^{\circ} \mathrm{C}$ for 1 day. The subsequent melt compounding of the PP nanocomposites was carried out using a co-rotating micro compounder Xplore $^{\mathrm{TM}}$ from DSM (Geleen, Netherlands) $(5.5 \mathrm{ml}$, $220^{\circ} \mathrm{C} 2 \mathrm{~min}, 120 \mathrm{rpm}$ ) and the micro injection molding device Xplore ${ }^{\mathrm{TM}}$ from DSM (Geleen, Netherlands) $\left(T_{\text {transfer }} 220^{\circ} \mathrm{C}, T_{\text {mold }} 60^{\circ} \mathrm{C}, p(\max )_{\text {injection }}\right.$ 9 bar). 


\subsection{Instrumental analysis}

Elemental analysis was performed with a VarioEl device (enrichment with $\mathrm{WO}_{3}$ ) from Elementaranalysesysteme $\mathrm{GmbH}$ (Hanau, Germany) to determine the content of carbon, hydrogen and nitrogen. The oxygen content was identified by energy dispersive X-ray scattering using a Quanta 250 FEG from FEI (Hillsboro, OR, USA) with an INCAx-act-add-on from Oxford Instruments (Abingdon, United Kingdom) and an acceleration voltage of $20 \mathrm{kV}$.

The specific surface area was characterized with a Sorptomatic 1990 from Porotec (Hofheim, Germany). The adsorption of nitrogen was measured according to Brunauer, Emmet and Teller analysis (BET).

Thermal properties were investigated by differential scanning calorimetry (DSC). Measurements were performed on a DSC 204 F1 Phoenix from Netzsch (Ahlden, Germany). Crystallization behavior was explored within the first cooling cycle owing a cooling rate of $10 \mathrm{~K} \cdot \mathrm{min}^{-1}$ within a temperature range of 30 $220^{\circ} \mathrm{C}$.

Electrical conductivity of the carbon-based nanofillers was detected by a four-point measurement arrangement. Therefore, a thin filler film $(d=41 \mathrm{~mm})$ was deposited by vacuum filtration on a polyesterbased membrane with an average pore size of $0.2 \mu \mathrm{m}$ from Pieper Filter GmbH (Bad Zwischenahn, Germany).

Fourier transform infrared (FT-IR) sprectra of the nanofillers were measured with a Vektor 22 from Bruker (Billerica, USA) using KBr tablets. 32 scans with a resolution of $2 \mathrm{~cm}^{-1}$ were recorded. All spectra are both background and baseline corrected.

Transmission electron microscopy for the characterization of the morphology was performed on a Zeiss LEO 912 from Omega (Oberkochen, Germany). The system was operated with an acceleration voltage of $120 \mathrm{kV}$. The powder specimen were deposited from a suspension in THF $\left(3 \mathrm{mg} \cdot \mathrm{ml}^{-1}\right)$ on a copper grid. The preparation of the ultrathin sections $(\sim 200 \mathrm{~nm})$ of the nanocomposites were carried out with a Leica Ultracut UCT microtome from Leica Microsystems (Wetzlar, Germany) $120^{\circ} \mathrm{C}$.

Further surface investigation by scanning electron microscopy (SEM) was performed on a Quanta 250 FEG from FEI (Hillsboro, USA) with an INCAx-addon from Oxford Instruments (Abingdon, United Kingdom). The system was operated with an acceleration voltage of $20 \mathrm{kV}$.
Surface sensitive chemical characterization of the powdery samples was conducted with an Axis Nova small spot X-ray photoelectron spectrometer from Kratos Analytics Ltd (Manchester, Great Britain). The powder was filled in a cavern shaped sample holder and slightly compressed manually. A spot size of $0.3 \times 0.75 \mu \mathrm{m}$ centered in the middle of the powder filled cavern was analyzed. Photoelectrons were generated by monochromatic $\mathrm{K}_{\alpha}$-line of aluminum (Al) at $1486.6 \mathrm{eV}$. The electron detector was adjusted to a pass energy of $160 \mathrm{eV}$ in the case of survey spectra or $20 \mathrm{eV}$ in the case of detail spectra, respectively. Charging effects were compensated by a self-balancing low electron energy neutralizer. The given binding energy scale was calibrated to the $\mathrm{C} 1 \mathrm{~s}$ line of aliphatic hydrocarbons at $285 \mathrm{eV}$ as reference.

The mechanical characterization was done with five test specimen for each sample in accordance to DIN ISO 527-1/2_5A. A Zwick Z-005 from ZwickRoell (Ulm, Germany) was used for the measurements with a test speed of $50 \mathrm{~mm} / \mathrm{min}$. Every test specimen was vertically aligned in a $2.5 \mathrm{kN}$ grip with a clamping length of $50 \mathrm{~mm}$. Tension was detected by a $5 \mathrm{kN}$ load sensor.

\subsection{Density functional theory calculations}

The simulations were performed using DFT within the projector augmented wave formalism [40] as implemented in the GPAW (Python code based on the projector augmented wave) package [41, 42]. The smooth parts of the Kohn-Sham wave-functions and of the electron density were represented on real space grids, where a grid spacing of about $0.2 \AA$ was applied for the wave-functions. The exchange correlation energy was approximated within the generalized gradient approximation as devised by Perdew et al. [43] (PBE). The results were cross checked including van der Waals contributions [44] (vdW-DF2).

\section{Results and discussion}

\subsection{Mechanochemically aminated graphene (AMFG)}

Two dry grinding processes were explored for mechanochemical amination and formation of aminefunctionalized multilayer graphene (AMFG) using a planetary ball mill. In order to prevent massive metal abrasion associated with the need of extensive purification, which is typical for MFG syntheses in steel mills, both milling chamber and balls were 
Table 1. Physical properties of carbon materials.

\begin{tabular}{|c|c|c|c|c|c|c|}
\hline Sample & $\begin{array}{c}C \\
{[w t \%]^{a}}\end{array}$ & $\begin{array}{c}\mathbf{H} \\
{[w t \%]^{\mathrm{a}}}\end{array}$ & $\begin{array}{c}O \\
{[w t \%]^{b}}\end{array}$ & $\begin{array}{c}\mathbf{N} \\
{[w t \%]^{\mathrm{a}}}\end{array}$ & $\begin{array}{c}\sigma \\
{\left[S \cdot \mathrm{cm}^{-1}\right]}\end{array}$ & $\begin{array}{c}\text { BET } \\
{\left[\mathrm{m}^{2} \cdot \mathrm{g}^{-1}\right]^{\mathrm{e}}}\end{array}$ \\
\hline Graphite-KFL & 99.6 & 0.2 & 1.2 & - & $3440^{c}$ & 1 \\
\hline AMFG(NH $\left(\mathrm{NH}_{3}-48 \mathrm{~h}\right)$ & 98.1 & 0.3 & 2.3 & 0.3 & $2340^{c}$ & 6 \\
\hline AMFG(NH $\left(\mathrm{NH}_{3}-96 \mathrm{~h}\right)$ & 94.6 & 0.5 & 3.5 & 0.5 & $1080^{\mathrm{c}}$ & 20 \\
\hline $\operatorname{AMFG}\left(\mathrm{Ar} / \mathrm{NH}_{3}\right)^{\mathrm{f}}$ & 86.8 & 1.0 & 6.8 & 3.2 & $0.5 \cdot 10^{-2 \mathrm{~d}}$ & 233 \\
\hline
\end{tabular}

a Determined by elemental analysis.

${ }^{b}$ Determined by energy-dispersive X-ray spectroscopy.

${ }^{\mathrm{c}}$ Four-point measurement using a pellet.

${ }^{\mathrm{d}}$ Four-point measurement using a coated filter.

${ }^{\mathrm{e} B E T}$ adsorption.

${ }^{\mathrm{f}}$ Two-stage milling at 13 bar Ar for $48 \mathrm{~h}$ during the first stage and 8.5 bar $\mathrm{NH}_{3}$ for $24 \mathrm{~h}$ in the second stage in the absence of oxygen.

made of abrasion resistant ceramics $\left(\mathrm{Y}_{0.05} \mathrm{Zr}_{0.95} \mathrm{O}_{2}\right)$. In the first process, similar to procedures reported by Jeon et al. [22] who used dry ice, pristine graphite (Graphite-KFL) was milled at ambient temperature under $\mathrm{NH}_{3}$ pressure ( 8.5 bar) for the duration of $48 \mathrm{~h}$ (AMFG(NH $\left.\left.\mathrm{NH}_{3}-48 \mathrm{~h}\right)\right)$ and $96 \mathrm{~h}\left(\mathrm{AMFG}\left(\mathrm{NH}_{3}-96 \mathrm{~h}\right)\right)$. In the second process graphite was milled first for the duration of $48 \mathrm{~h}$ under argon pressure (13 bar) to produce MFG-Ar containing reactive carbon. Then argon was substituted for ammonia ( $8.5 \mathrm{bar}$ ) in the absence of oxygen and milling was continued for the duration of $6,12,18$ and $24 \mathrm{~h}$ prior to pressure relief and exposure to air and moisture. The properties of the resulting AMFG materials are listed in Table 1. The AMFG and graphite morphologies, as determined by means of photography, scanning electron microscopy (SEM) and transmission electron microscopy (TEM) are displayed in Figure 1. From Table 1 it is apparent that even after prolonged grinding for $96 \mathrm{~h}$ at $8.5 \mathrm{bar}$ of $\mathrm{NH}_{3}$ pressure in the one-stage process, the nitrogen content of AMFG, as measured by elemental analysis, was below $0.5 \mathrm{wt} \%$ paralleled by high carbon content $>94 \%$. This is in sharp contrast to milling under argon, nitrogen and carbon dioxide at similar pressure, producing MFG with carbon content well below 90\% [22]. Another striking difference relates to the carbon particle morphology displayed in Figure 1. Prolonged milling under argon (see $\operatorname{MFG}\left(\mathrm{Ar} / \mathrm{NH}_{3}\right)$ in Figure 1) as well as nitrogen or carbon dioxide at similar pressures drastically reduced the average particle sizes and destroyed platelettype carbon morphology typical for graphite. In contrast, milling graphite under 8.5 bar ammonia pressure preserved the large graphite platelets $(100 \mu \mathrm{m})$ and only marginally enhanced the specific surface area. This result differs from reports by Jeon and coworkers [22, 33-36] concerning shear induced delamination of graphite forming $\mathrm{FG}$ with a lower aspect ratio. $\mathrm{Ob}-$ viously, the presence of ammonia inhibited the breakage of carbon-carbon bonds of graphite when exposed to high shear forces in a planetary ball mill. This is in accord with reports by Xing et al. [45] who first observed the surprising indestructible behavior of 2D nanomaterials upon dry ball-milling in the presence of ammonia or ethylene gas, respectively. Backed by DFT calculations they assumed that this 'gas protection against high-energy impact' was attributed chemisorption and reaction of $\mathrm{NH}_{3}$ at defect sites and healing defects by saturating dangling bonds. The electrical conductivities of the resulting AMFG( $\left(\mathrm{NH}_{3}-48 \mathrm{~h}\right)$ and $\mathrm{AMFG}\left(\mathrm{NH}_{3}-96 \mathrm{~h}\right)$ samples were only marginally lower with respect to that of graphite.

In the two-stage milling process, graphite was milled first at 13 bar argon pressure and then under ammonia pressure ( 8.5 bar) in the absence of oxygen. Although argon is completely inert, milling under argon breaks up the graphite particles, as evidenced by formation of spherical carbon nanoparticles and the absence of platelets. Upon the exposure to air and moisture when opening the milling chamber, a vigorous reaction takes place and highly reactive yet unknown carbon species react with oxygen to form mainly hydroxyl groups. In the two-stage milling process argon was substituted for ammonia prior to contact with air. As seen in Figure 2, the nitrogen content markedly increased during the second milling stage under $\mathrm{NH}_{3}$ pressure from $1.9 \mathrm{wt} \%$ after milling for $6 \mathrm{~h}$ to $3.2 \mathrm{wt} \%$ after $24 \mathrm{~h}$. This increase of nitrogen content by one order of magnitude is attributed to the reaction of ammonia with reactive carbon species, which are generated in the first milling-stage. Upon exposure to air, no highly exothermic reaction with oxygen was observed. 

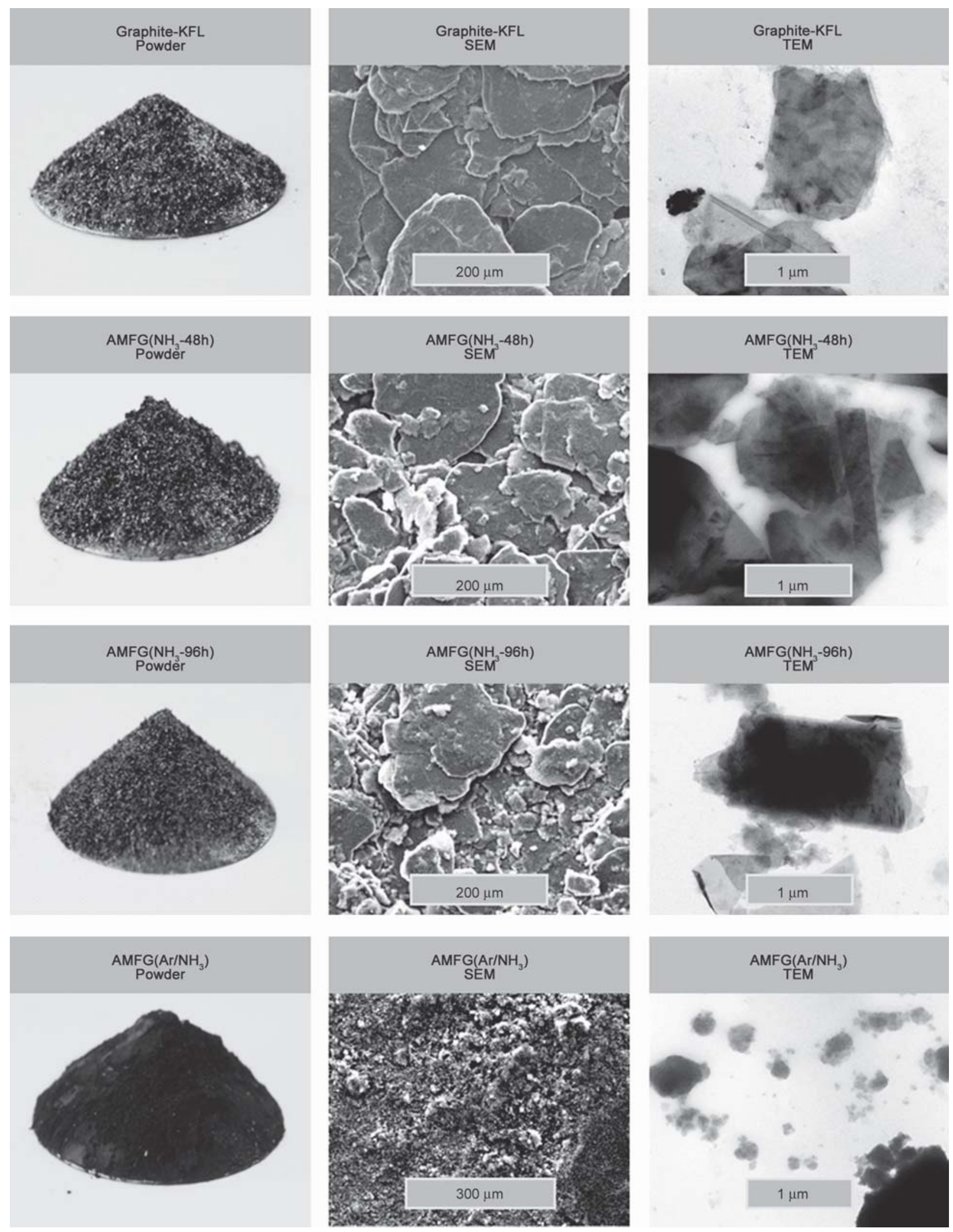

Figure 1. Morphology of AFMG and graphite (Graphite-KFL) as determined by photographic imaging (left), SEM (center) and TEM (right).

XPS measurements confirmed nitrogen incorporation by the two-stage milling process. Figure 3 displays XPS spectra of graphite and AMFG(Ar/ $\left./ \mathrm{NH}_{3}\right)$. Whereas the spectrum of pristine graphite shows a dominant $\mathrm{C} 1 \mathrm{~s}$ and a weak $\mathrm{O} 1 \mathrm{~s}$ signal at 285.0 and $533.3 \mathrm{eV}$, the XPS spectrum of AMFG(Ar/ $\left./ \mathrm{NH}_{3}\right)$ reveals a small $\mathrm{N} 1 \mathrm{~s}$ signal at $400.1 \mathrm{eV}$ in addition to a strong $\mathrm{C} 1 \mathrm{~s}$ and a weak $\mathrm{O} 1 \mathrm{~s}$ signal with a binding 


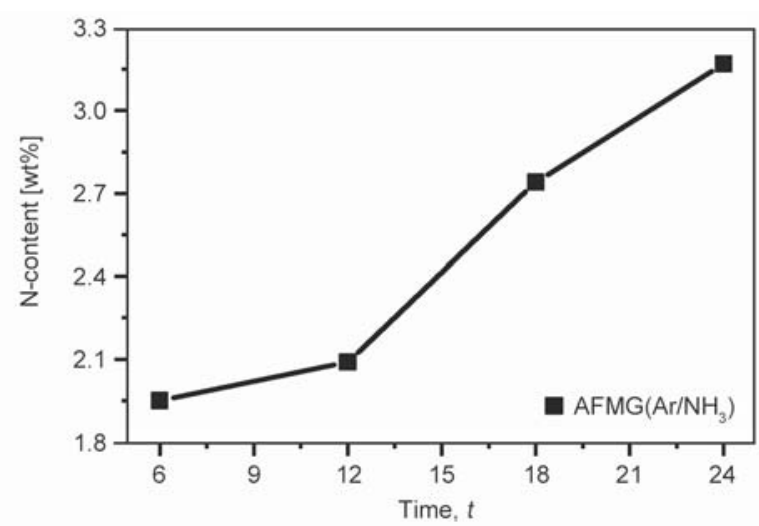

Figure 2. Nitrogen content as a function of the duration of milling under ammonia pressure $(8.5 \mathrm{bar})$ in the second ball-milling stage following $48 \mathrm{~h}$ of milling under argon pressure (13 bar) in the first stage.

energy of 285.0 and $532.2 \mathrm{eV}$, respectively. In accordance with the literature, the N1s signal at $400.1 \mathrm{eV}$ is assigned to $\mathrm{C}-\mathrm{N}$-binding of a primary amine $[46,47]$.

Simulations of graphite dry grinding under argon, carbon dioxide, nitrogen and ammonia pressure were performed using DFT within the projector augmented wave formalism [40] as implemented in the GPAW package [41, 42]. The smooth parts of the KohnSham wave-functions and of the electron density were represented on real space grids, where a grid spacing of about $0.2 \AA$ was applied for the wavefunctions. The exchange correlation energy was approximated within the generalized gradient approximation as devised by Perdew, Burke and Ernzerhof [43] (PBE). The results were cross checked including van der Waals contributions [44] (vdW-DF2). Experimental lattice parameters of graphite $(a=$ $1.42 \AA, c=3.35 \AA$ ) are used to set up the graphite $\mathrm{C}_{36}$ unit cell in $\mathrm{AB}$ stacking. Periodic boundary conditions were applied in all directions and $(2 \times 2 \times 2)$
Monkhorst and Pack [48] distributed $k$-points were used to sample the Brillouine zone. The structures were relaxed without symmetry restrictions until all forces were below $0.05 \mathrm{eV} / \AA$. The unit cell was kept fixed during relaxation of the atomic positions. This strategy can be seen as a model for a region that is surrounded by large unperturbed bulk graphite. Figure 4 shows relaxed positions of the molecules $\mathrm{Ar}$, $\mathrm{CO}_{2}, \mathrm{~N}_{2}$ and $\mathrm{NH}_{3}$, after the molecules have been placed between the layers in the $\mathrm{C}_{36}$ model. $\mathrm{Ar}, \mathrm{CO}_{2}$ and $\mathrm{N}_{2}$ disturb the graphene lattice, but stay mainly intact. The $\mathrm{NH}_{3}$ molecule forms a bond to a carbon atom with bond-length $R_{\mathrm{CN}}=1.48 \AA$, very similar to a methylamine bond (1.47 $\AA$ ).

In order to explore the interlayer-mobility of the gases we have forced their movement with respect to the graphene lattice. In this simulation one graphite carbon atom was held fixed, while one of the atoms of the gaseous molecule is forced to move parallel to the graphene-layers (the x-direction) in steps of $\mathrm{d} x=0.25 \AA$. All other atoms are allowed to relax without symmetry restrictions. The energetics for these movements is shown in Figure 5a. The gases Ar, $\mathrm{CO}_{2}$ and $\mathrm{N}_{2}$ show a rather flat energy for this motion with energy variations below $0.15 \mathrm{eV}(1 \mathrm{eV}=$ $98.49 \mathrm{~kJ} / \mathrm{mol}$ ). These energy barriers are equal to or even lower than the barriers experienced by graphite intercalated alkali metals [49]. Therefore, comparably fast diffusion between the layers can be expected for $\mathrm{Ar}, \mathrm{CO}_{2}$ and $\mathrm{N}_{2}$. In contrast, $\mathrm{NH}_{3}$ experiences rather high energy barriers of up to $0.9 \mathrm{eV}$. The reason is constant breaking and reformation of $\mathrm{C}-\mathrm{N}$ bonds as seen in Figure 5b. The $\mathrm{NH}_{3}$ molecules appear to be bound to carbon atoms all the time as is shown by their small minimal bond length $R_{\mathrm{CN}}$ that is similar to a methylamine bond $(1.47 \AA)$. These

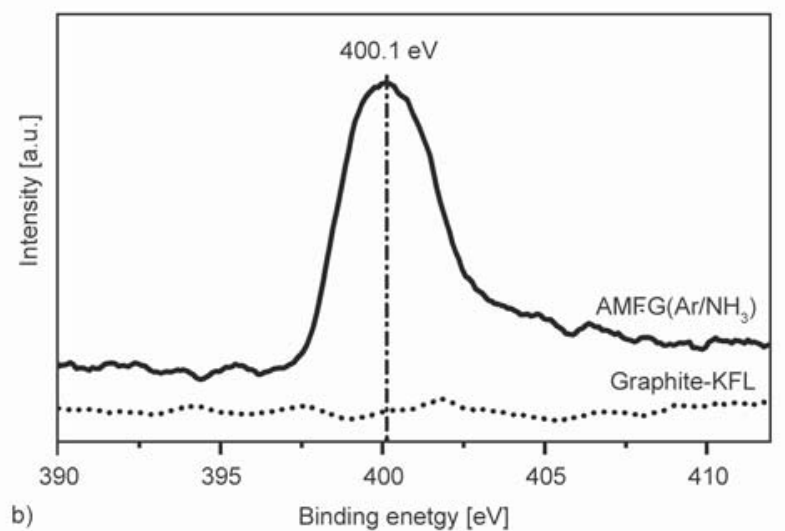

b)

a)

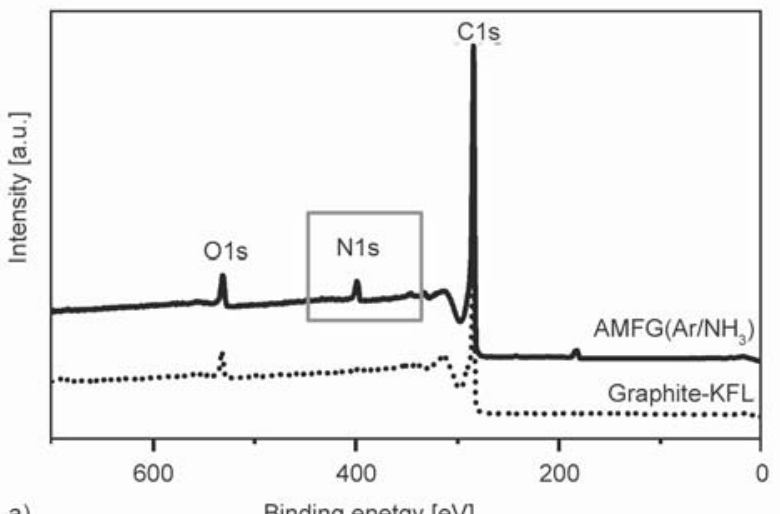

Figure 3. XPS-spectra of graphite (dotted line) and AMFG(Ar/ $\left.\mathrm{NH}_{3}\right)$ (solid line) with survey spectrum (a) and magnification
of the N1s signal (b). of the N1s signal (b). 

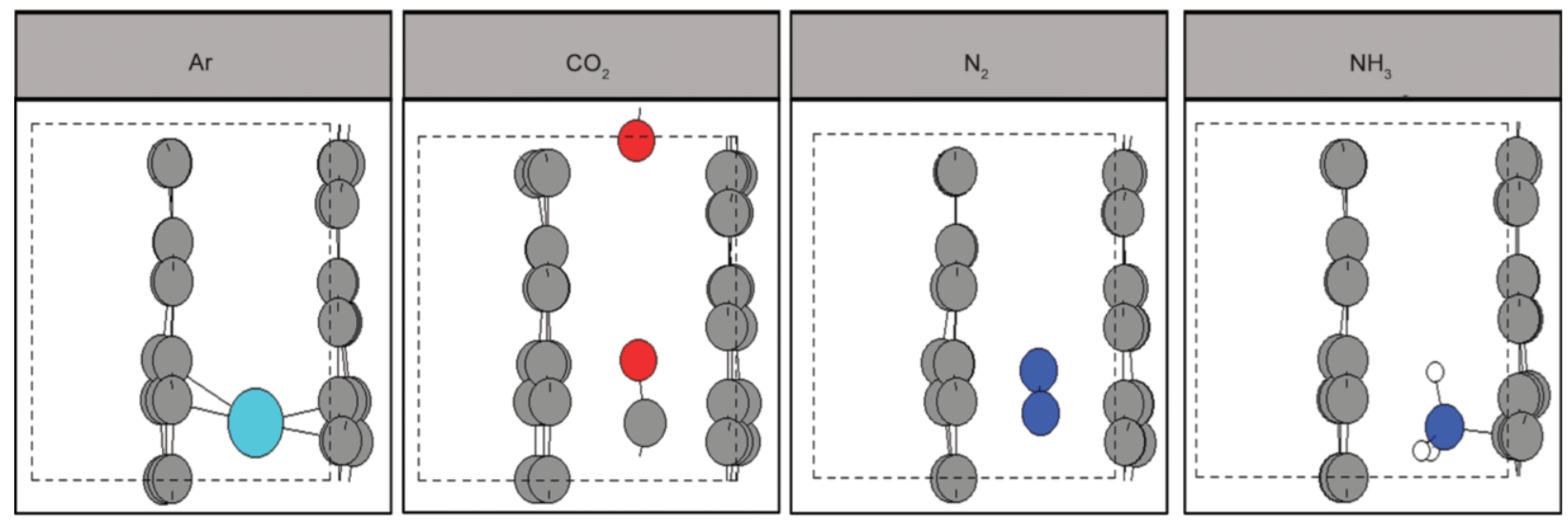

Figure 4. Unit cell of 36 carbon atom graphite (two layers) with inclusions of $\mathrm{Ar}, \mathrm{CO}_{2}, \mathrm{~N}_{2}$ and $\mathrm{NH}_{3}(\mathrm{C}=\mathrm{grey}, \mathrm{Ar}=$ light blue, $\mathrm{O}=$ red, $\mathrm{N}=$ blue, $\mathrm{H}=$ white). The thin connecting lines are chosen according to the atom-atom distance to guide the eye.

bonds make the molecules very immobile and lets the molecules stick to their initial position. This result is independent of the function applied and is present most of the time during the movement as indicated by the small bond-lengths of $R_{\mathrm{CN}}<1.7 \AA$. The bonding observed in Figure $5 \mathrm{~b}$ is a result of the pressure on the molecules due to the confinement between the graphene layers as can be seen from Figure 6. In these simulations the dimension of the unit cell is varied in the direction of the graphene layers surface normal in steps of $0.1 \AA$. The pressure is calculated from the total energy change due to these unit cell changes. Decreasing the unit cell corresponds to an increase of pressure, while enlarging the unit cell corresponds to a pressure release. Bonding $\left(R_{\mathrm{CN}}<1.7 \AA\right)$ is observed for pressures above $10 \mathrm{GPa}$. The functional approximation including van der Waals contributions with vdW-DF2 gives a lower binding tendency but qualitatively predicts the same effect. There is a hysteresis when switching from a
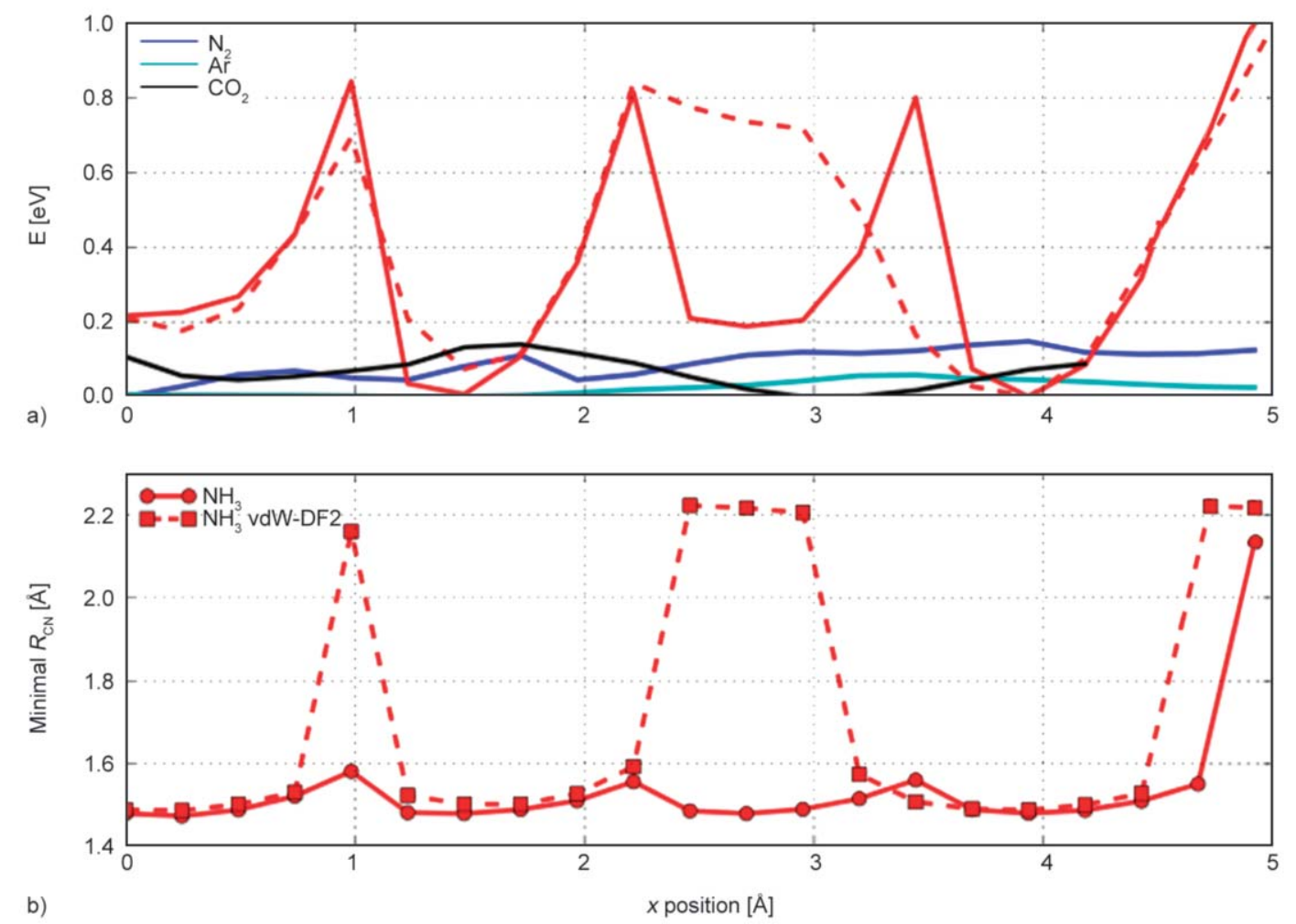

Figure 5. a) Energies needed for translational motion in $x$-direction for the molecules of our study and b) corresponding minimal CN bond-length $R_{\mathrm{CN}}$ for the movement of $\mathrm{NH}_{3}$. Solid lines correspond to PBE and broken lines to vdW-DF2 approximations. 

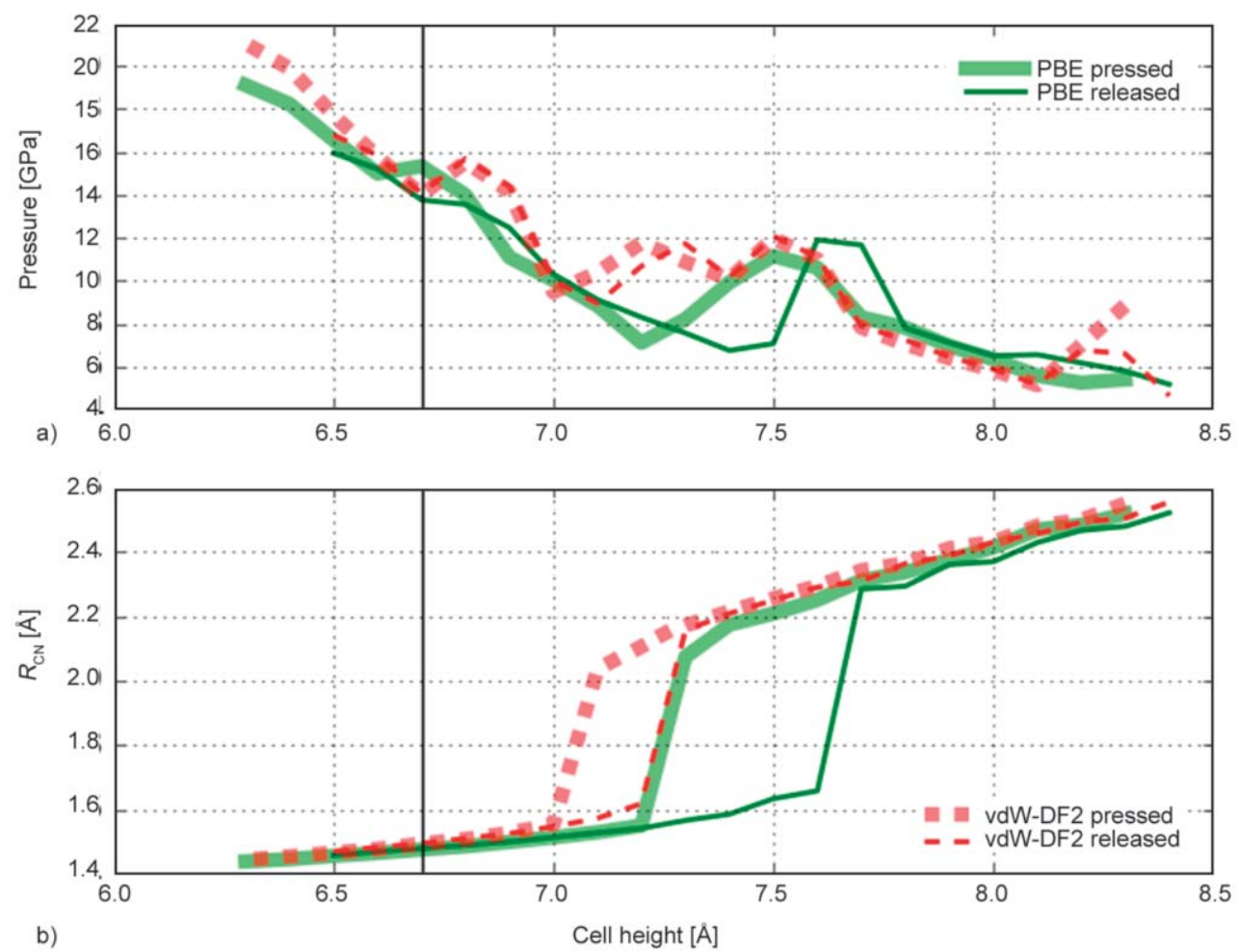

Figure 6. Pressure (a) and $\mathrm{C}-\mathrm{N}$ distance $R_{\mathrm{CN}}$ (b) obtained in the $\mathrm{C}_{36}$ unit cell. Solid lines are for simulations where the unit cell is released in the direction of the carbon sheet surface normal (z-direction), while broken lines are simulations where the unit cell is reduced in z-direction. See Figure 1 for the definition of the coordinate system.

release of the unit cell to reduction of the cell suggesting the existence of a barrier. The pressure in a blister of graphene on graphite was estimated to be 5-6 GPa [50] which is slightly lower than the pressure needed to create the $\mathrm{CN}$ bond. The pressure inside graphite might be larger and the presence of pressures above $10 \mathrm{GPa}$ are expected in ball milling $[51,52]$. This simulation is in accordance with experimental observation that in a one-stage process the functionalization and graphite exfoliation under ammonia pressure is much less effective with respect to milling under argon, nitrogen and carbon dioxide pressure. However, in a two-stage process with grinding under argon in the first stage, graphite exfoliation and higher amine functionality are achieved as reactive carbon sites produced in the first stage react with $\mathrm{NH}_{3}$ in the second stage.

\subsection{Model reaction for carbon/polymer hybrid formation by imide coupling}

The AMFG amine groups can react with succinic anhydride groups of various anhydride-functional polymers such as polypropylene (PP) grafted with maleic anhydride (MA) to produce a wide range of carbon/ polymer hybrid materials comprising AMFG graft copolymers with covalent imide coupling between
AMFG and the maleated polymer. The reactivity of the AMFG amine groups with respect to imide formation was examined by means of a model reaction using 2-octen-1-yl-succinic anhydride (OSA) as model for PP-g-MA. Typically, AMFG( $\left.\mathrm{Ar} / \mathrm{NH}_{3}\right)$ was reacted with refluxing OSA. After removal of excess OSA, the formation of imide-functionalized graphene (IMFG) was monitored by means of FT-IR spectroscopy. In Figure 7 the FT-IR spectrum of IMFG and the one of pristine graphite and $\mathrm{AMFG}\left(\mathrm{Ar} / \mathrm{NH}_{3}\right)$ are compared.

The formation of imide groups present in IMFG was confirmed by the presence of a $\mathrm{C}=\mathrm{O}$ stretching vibration at $1720 \mathrm{~cm}^{-1}$ and $\mathrm{C}-\mathrm{N}$ vibration at $1230 \mathrm{~cm}^{-1}$ (Figure 7, iii). Additionally, the FT-IR spectroscopy indicated the presence of the aliphatic succinic groups in the range of $3000-2930 \mathrm{~cm}^{-1}$. The covalent imide coupling was accompanied by a shift of the carbonyl bands from 1785 to $1720 \mathrm{~cm}^{-1}$ when comparing OSA and IMFG. Moreover, the FT-IR spectrum of AMFG(Ar/ $\mathrm{NH}_{3}$ ) (Figure 7, ii) showed weak $\mathrm{C}-\mathrm{H}$ bending vibrations at $1430 \mathrm{~cm}^{-1}$ together with a broad $\mathrm{C}-\mathrm{N}$ stretching vibration at $1230 \mathrm{~cm}^{-1}$. Due to the strong forces during the milling process the aromatic system cracked while generating defects that were subsequently saturated by forming aliphatic groups. 


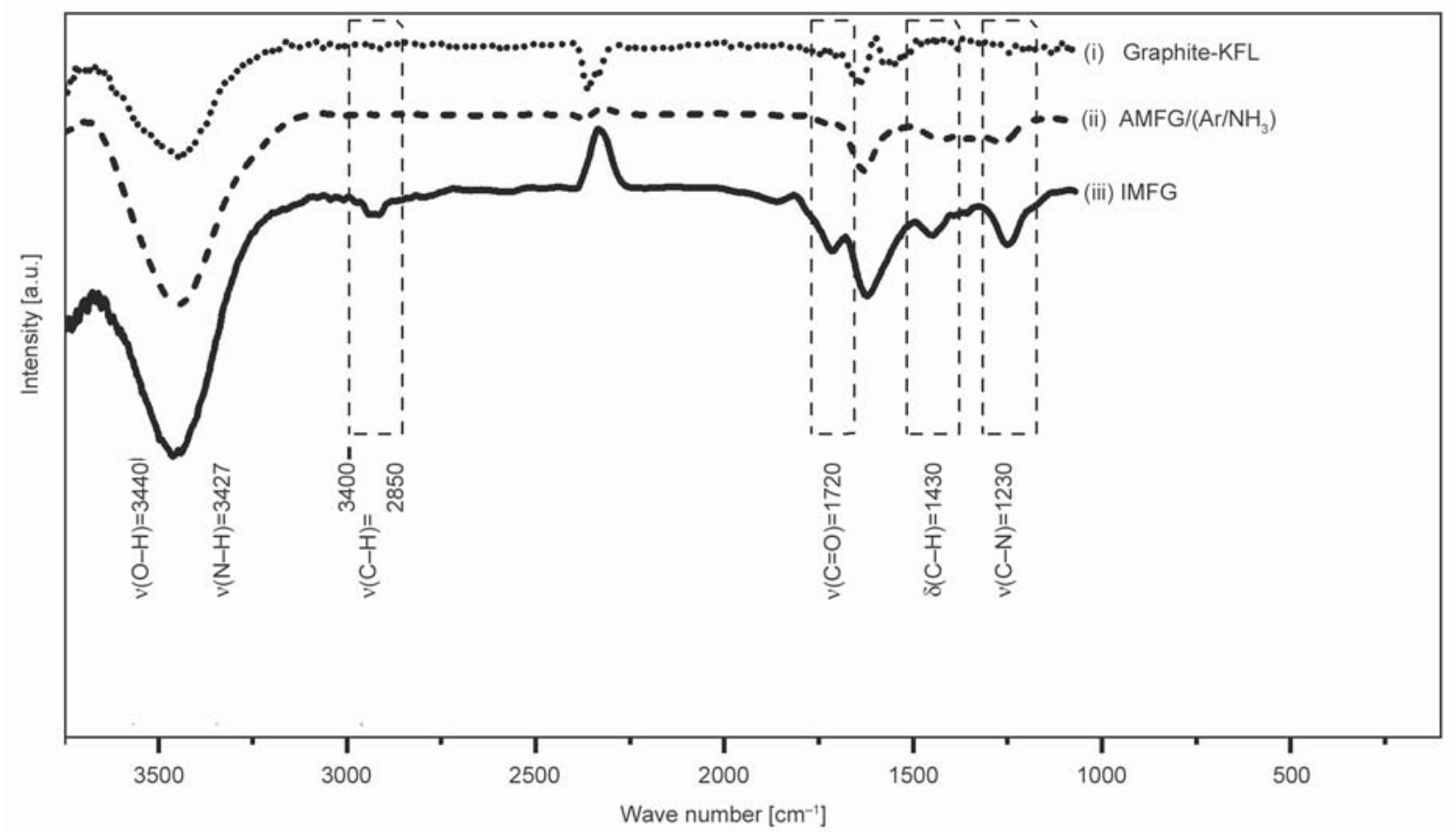

Figure 7. FT-IR spectra of graphite (i, dotted line), $\mathrm{AMFG}\left(\mathrm{Ar} / \mathrm{NH}_{3}\right)$ (ii, dashed line) and IMFG (iii, solid line).

The detection of the $\mathrm{N}-\mathrm{H}$ signals was severely impeded due to strong bands resulting from absorbed water and the aromatic $\mathrm{C}=\mathrm{C}$ vibration in the same range. In view of the nitrogen content of $3.2 \mathrm{wt} \%$, as determined by elemental analysis, the detection by FT-IR spectroscopy reached its limits. Unfunctionalized graphite (i) showed strong IR bands in the range of 1640 to $1570 \mathrm{~cm}^{-1}$ typical for the presence of aromatic carbon structures. Additionally, there was a broad vibrational band of hydroxylic groups at $3440 \mathrm{~cm}^{-1}$ most likely resulting from water absorbed either by graphite or $\mathrm{KBr}$. This FT-IR spectroscopic model reaction confirmed that the $\mathrm{AMFG}\left(\mathrm{Ar} / \mathrm{NH}_{3}\right)$ amine groups covalently couple with the succinic anhydride groups via imide formation to form IMFG.

\subsection{Carbon/PP nanocomposites}

AMFG(Ar/ $\left.\mathrm{NH}_{3}\right)$, prepared in the two-stage milling process and containing $3.2 \mathrm{wt} \%$ nitrogen, was melt compounded with PP and compared with the commercial non-functionalized micronized graphite platelets $\mathrm{G}(1.5 \mu \mathrm{m})$. The filler $\mathrm{G}(1.5 \mu \mathrm{m})$ has an average particle size of $1.5 \mu \mathrm{m}$ and a high carbon content of $99.3 \mathrm{wt} \%$. Melt compounding was performed by means of a twin-screw mini extruder in both the absence and the presence of $10 \mathrm{wt} \%$ maleated PP (PP-g-MA) corresponding a total content of $1 \mathrm{wt} \%$ grafted maleic anhydride groups. Coupling of AMFG(Ar/ $\left.\mathrm{NH}_{3}\right)$ with PP-g-MA via imide group formation during melt compounding produced insitu PP-grafted IMFG serving as compatibilizer. The influences of both filler type and content on thermal and mechanical properties of AMFG(Ar/ $\left./ \mathrm{NH}_{3}\right) / \mathrm{PP}$ and $\mathrm{G}(1.5 \mu \mathrm{m}) / \mathrm{PP}$ compounds processed by means of injection molding are summarized in Table 2 and graphically displayed Figure 8.

Similar to other PP melt compounds containing carbon nano and micro platelets $[37,53]$ the dispersion of both $\mathrm{AMFG}\left(\mathrm{Ar} / \mathrm{NH}_{3}\right)$ and $\mathrm{G}(1.5 \mu \mathrm{m})$ enhanced both stiffness, as expressed by increased Young's modulus, and tensile strength at the expense of elongation at break. The addition of AMFG(Ar/ $\left./ \mathrm{NH}_{3}\right)$ or $\mathrm{G}(1.5 \mu \mathrm{m})$, respectively, afforded similar increases of Young's modulus of +25 to $+40 \%$ at $10 \mathrm{wt} \%$ and of +50 to $+105 \%$ at $20 \mathrm{wt} \%$ carbon filler in the absence and presence of PP-g-MA accompanied by severely impairing elongation at break (Figure 8). However, at $10 \mathrm{wt} \% \mathrm{AMFG}\left(\mathrm{Ar} / \mathrm{NH}_{3}\right)$ content only in the presence of PP- $g$-MA the loss of elongation at break $(20 \%)$ was considerably lower with respect to the other carbon fillers (70 to 99\%). Although the addition of $10 \mathrm{wt} \%$ PP-g-MA adversely affected tensile strength of PP/PP-g-MA, the addition of both carbon fillers improved tensile strength but did not show significant difference for the presence of amine groups.

From SEM images of fracture surfaces displayed in Figure 9 it is apparent that at $10 \mathrm{wt} \%$ carbon filler 
Table 2. Mechanical and thermal properties of carbon/PP nanocomposites.

\begin{tabular}{|c|c|c|c|c|c|c|}
\hline \multicolumn{1}{|c|}{ Sample } & $\begin{array}{c}\text { Filler content } \\
{[\mathbf{w t} \mathbf{0}]}\end{array}$ & $\begin{array}{c}\text { Young's modulus } \\
{[\mathbf{M P a}]}\end{array}$ & $\begin{array}{c}\text { Tensile strength } \\
{[\mathbf{M P a}]}\end{array}$ & $\begin{array}{c}\text { Elongation at break }^{\mathbf{a}} \\
{[\mathbf{\%}]}\end{array}$ & $\begin{array}{c}\boldsymbol{T}_{\mathbf{c}}^{\mathbf{b}} \\
{\left[{ }^{\mathbf{C}} \mathbf{C}\right]}\end{array}$ & $\begin{array}{c}\Delta \boldsymbol{H}_{\mathbf{c}}^{\mathbf{b}} \\
{[\mathbf{J} / \mathbf{g}]}\end{array}$ \\
\hline $\mathrm{PP}$ & - & $1270 \pm 50$ & $33.4 \pm 0.1$ & $975 \pm 20$ & 114 & 92 \\
\hline$+\mathrm{G}(1.5 \mu \mathrm{m})$ & 10 & $1770 \pm 55$ & $37.4 \pm 0.5$ & $250 \pm 15$ & 124 & 96 \\
\hline$+\mathrm{G}(1.5 \mu \mathrm{m})$ & 20 & $1980 \pm 50$ & $37.3 \pm 0.2$ & $140 \pm 60$ & 125 & 107 \\
\hline$+\mathrm{AMFG}\left(\mathrm{Ar} / \mathrm{NH}_{3}\right)$ & 10 & $1630 \pm 120$ & $33.9 \pm 0.6$ & $280 \pm 20$ & 122 & 93 \\
\hline$+\mathrm{AMFG}\left(\mathrm{Ar} / \mathrm{NH}_{3}\right)$ & 20 & $1870 \pm 50$ & $35.4 \pm 0.8$ & $12 \pm 2$ & 128 & 100 \\
\hline $\mathrm{PP}+\mathrm{PP}-\mathrm{g}-\mathrm{MA}$ & - & $1200 \pm 20$ & $30.9 \pm 0.7$ & $385 \pm 45$ & 112 & 91 \\
\hline & 10 & $1610 \pm 140$ & $33.4 \pm 1.1$ & $16 \pm 5$ & 124 & 97 \\
\hline$+\mathrm{G}(1.5 \mu \mathrm{m})$ & 20 & $2480 \pm 120$ & $34.8 \pm 1.0$ & $3.2 \pm 1.1$ & 128 & 101 \\
\hline$+\mathrm{G}(1.5 \mu \mathrm{m})$ & 10 & $1505 \pm 40$ & $33.9 \pm 0.6$ & $300 \pm 10$ & 118 & 101 \\
\hline$+\mathrm{AMFG}\left(\mathrm{Ar} / \mathrm{NH}_{3}\right)$ & 20 & $1910 \pm 40$ & $35.4 \pm 0.8$ & $15 \pm 5$ & 120 & 103 \\
\hline
\end{tabular}

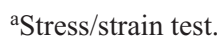

${ }^{\mathrm{b}}$ First DSC cooling cycle.
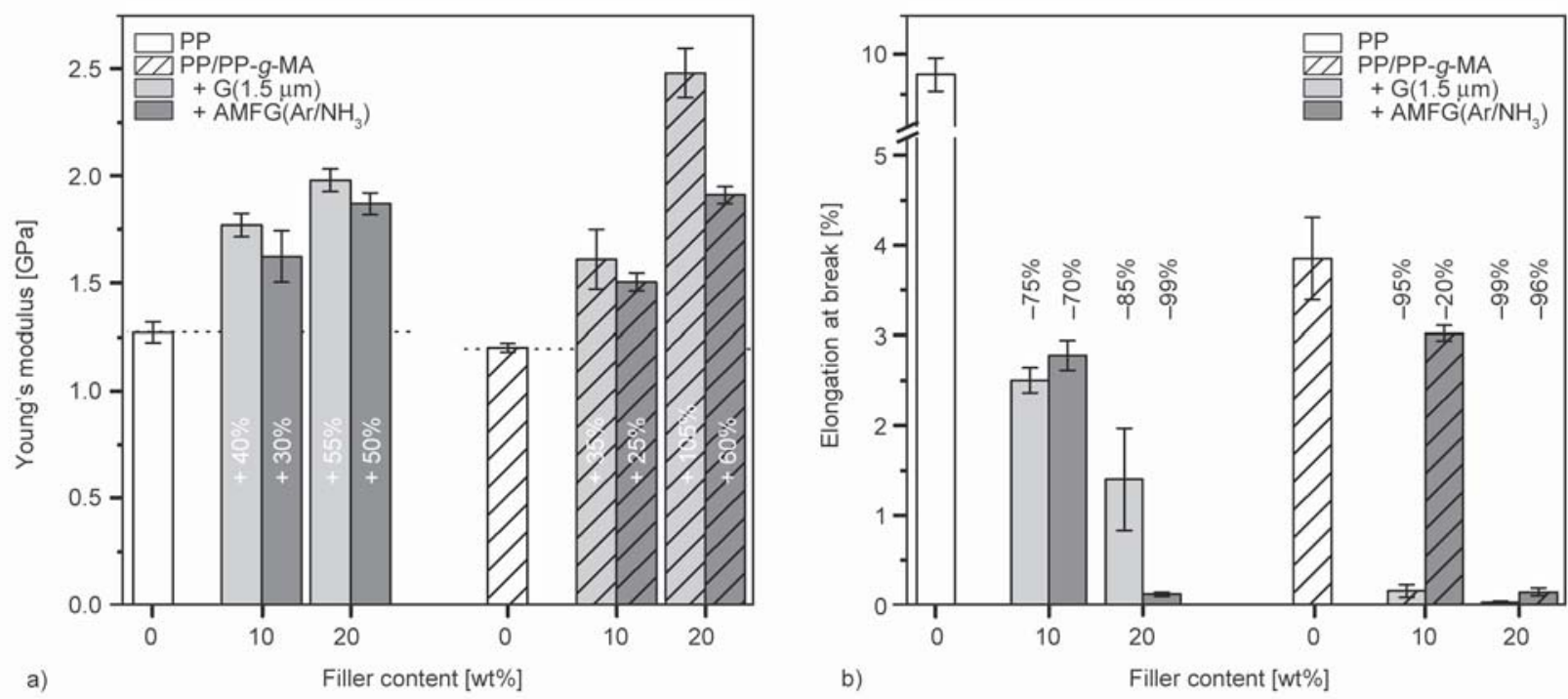

Figure 8. Young's modulus (a) and elongation at break (b) of PP (white), PP/PP- $g$-MA (white, cross-hatched), G(1.5 $\mu \mathrm{m}$ )/PP (light grey) and AMFG/PP (grey), compounds as a function of carbon filler type and content in the presence (crosshatched) and absence (solid) of PP-g-MA.

content only the presence of PP- $g$-MA accounted for much better dispersion of both carbon fillers. The presence of large particles visible in the case of AMFG( $\left.\mathrm{Ar} / \mathrm{NH}_{3}\right)$ is attributed to the rather broad particle size distribution containing nanometer- as well as micron-sized carbon particles. Crystallization temperature $\left(T_{\mathrm{c}}\right)$ and enthalpy $\left(\Delta H_{\mathrm{c}}\right)$ were analyzed by DSC (see Table 2). Similar to other carbon nanoparticles $[35,50]$ both micronized graphite $\mathrm{G}(1.5 \mu \mathrm{m})$ and $\mathrm{AMFG}\left(\mathrm{Ar} / \mathrm{NH}_{3}\right)$ nucleated PP crystallization in the absence and the presence of PP-gMA as verified by 6 to $16^{\circ} \mathrm{C}$ higher crystallization temperature. Nucleation was unaffected by the presence of amine groups and amine coupling with PP$g$-MA. Higher crystallinity resulting from nucleation of PP crystallization by both carbon filler contributed to PP stiffness enhancement.

The performance of carbon/PP composites containing $10 \mathrm{wt} \%$ micronized graphite and aminated multilayer graphene $\mathrm{AMFG}\left(\mathrm{Ar} / \mathrm{NH}_{3}\right)$ are compared in the spider diagrams displayed in Figure 10. In the absence and presence of PP- $g$-MA the addition of $\mathrm{G}(1.5 \mu \mathrm{m})$ platelets accounted for higher stiffness and improved nucleation of PP crystallization with respect to spherical $\mathrm{AMFG}\left(\mathrm{Ar} / \mathrm{NH}_{3}\right)$ as expected for fillers with higher aspect ratio. The addition of both fillers caused similar losses of elongation at break in the absence of PP-g-MA. However, in the presence of PP-g-MA the elongation at break was markedly higher for $\mathrm{AMFG}\left(\mathrm{Ar} / \mathrm{MH}_{3}\right)$ which is likely to react 

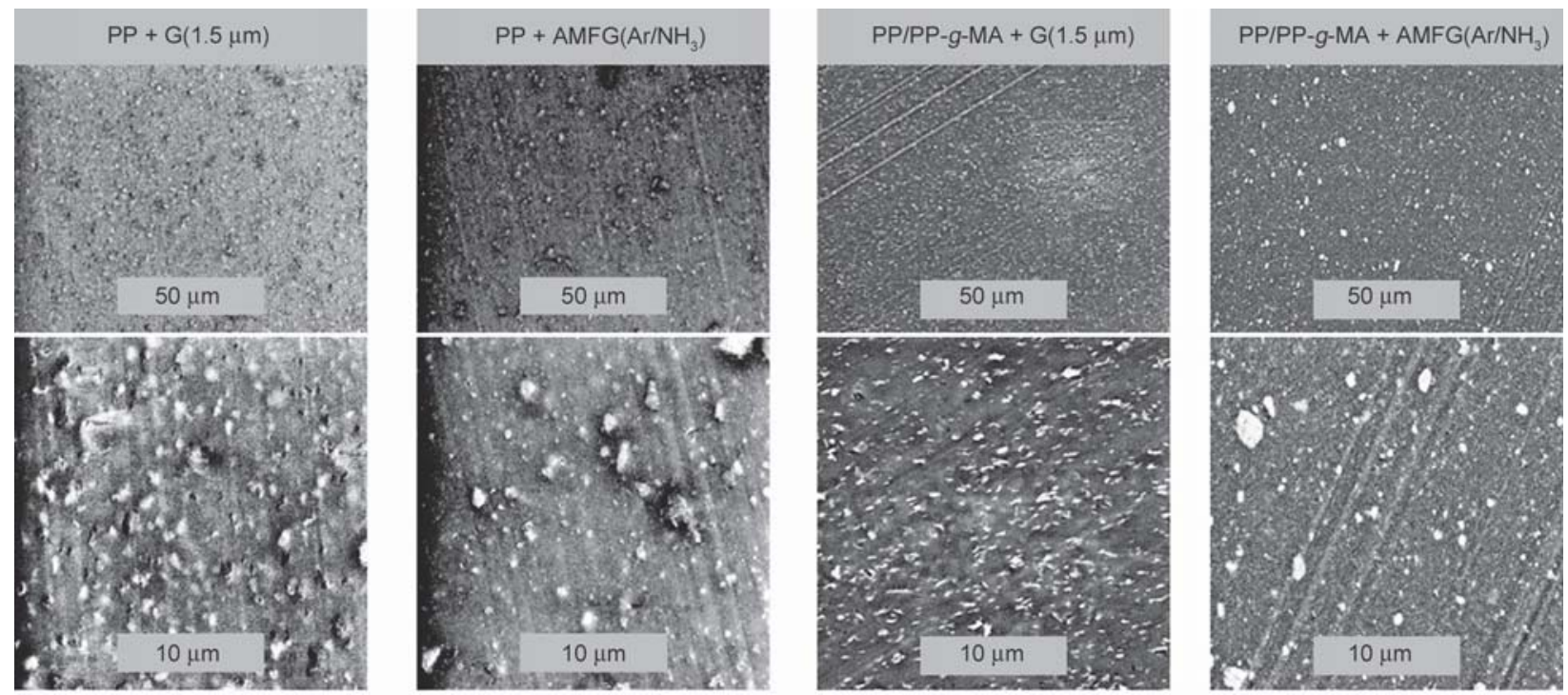

Figure 9. SEM images of carbon/PP fracture surfaces of carbon/PP composites containing $10 \mathrm{wt} \%$ carbon filler in the absence and in the presence of PP- $g$-MA.
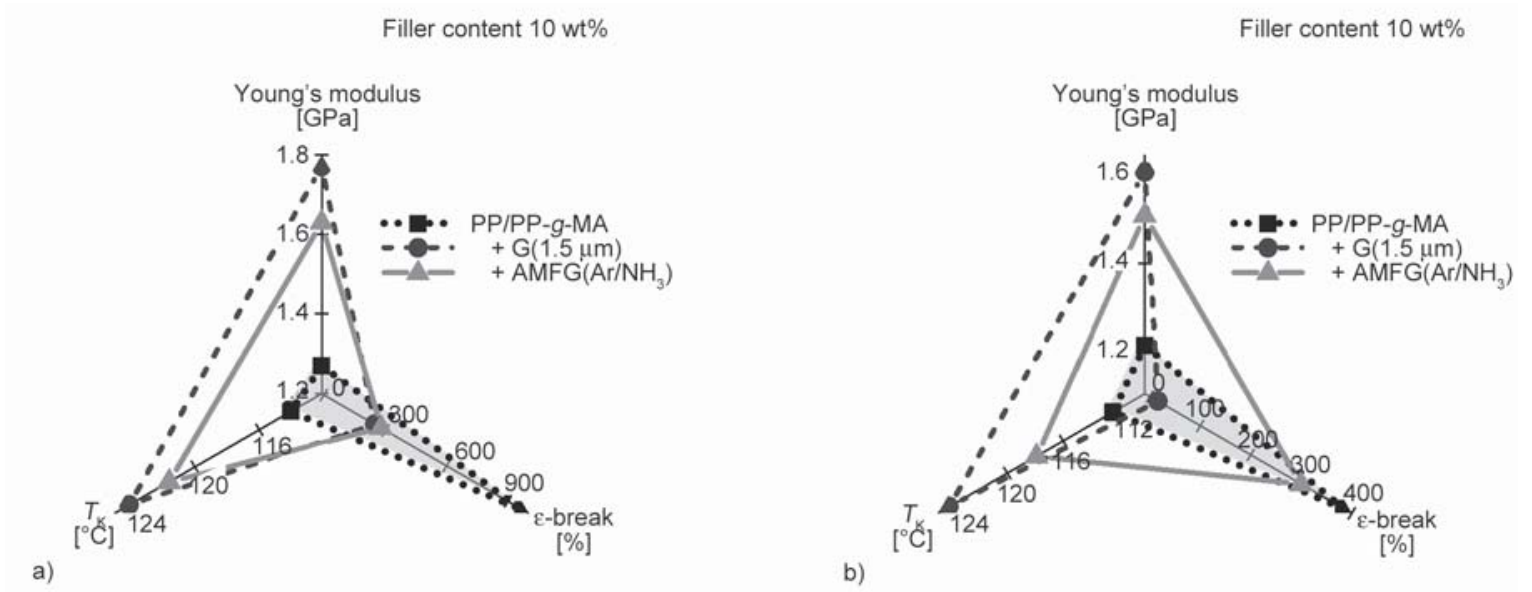

Figure 10. Comparison carbon/PP compounds containing $10 \mathrm{wt} \%$ of either non-functionalized G(1.5 $\mu \mathrm{m})$ or aminated $\mathrm{AMFG}\left(\mathrm{Ar} / \mathrm{NH}_{3}\right)$ in the absence (a) and presence (b) of $10 \mathrm{wt} \% \mathrm{PP}-\mathrm{g}-\mathrm{MA}$.

with PP-g-MA, thus grafting PP onto AMFG via imide coupling.

\section{Conclusions}

Mechanochemically aminated multilayer graphene (AMFG) is produced by two-stage dry ball milling of graphite in a planetary ball mill under argon followed by ammonia pressure. The use of milling container and balls made of abrasion resistant zirconate ceramics eliminates metal abrasion and tedious removal of metal impurities typical for stainless steel. The resulting nanometer-scaled AMFG( $\left.\mathrm{Ar} / \mathrm{NH}_{3}\right)$ is an attractive intermediate for melt processing of carbon/polypropylene nanocomposites and for grafting maleated polypropylene onto carbon via covalent imide coupling. Opposite to dry ball milling under argon, nitrogen and carbon dioxide pressure, the one-stage ball milling of graphite under 8.5 bar ammonia pressure affords rather low nitrogen content $(<0.5 \mathrm{wt} \%)$ even after prolonged milling for $96 \mathrm{~h}$ and the large graphite micron-sized graphite platelets are unaffected. According to simulations by DFT calculations on carbon model systems argon, carbon dioxide and nitrogen massively disturb the graphene lattice but stay intact whereas ammonia forms very week bonds to a carbon and exhibits considerably lower mobility between graphene layers. In accordance with earlier observations by Xing et al. [45] both breakage of $\mathrm{C}-\mathrm{C}$ bonds and the reaction of reactive carbon atoms with $\mathrm{NH}_{3}$ are prevented. With increasing milling duration in the second stage the nitrogen content of the resulting AMFG increases by one order of magnitude to $3.2 \mathrm{wt} \%$. The presence of primary amine groups is verified by XPS measurement and by 
IR spectroscopic proof of imide formation upon reacting the amine groups with a dicarboxylic acid anhydride. This covalent imide coupling enables to graft maleated polymers such as PP-g-MA onto carbon nanoparticles, thus producing new families of carbon/polymer hybrid materials. They are of interest as compatibilizers improving dispersion and interfacial adhesion of carbon nanofillers in various polymers. Both micronized graphite and AMFG( $\left.\mathrm{Ar} / \mathrm{NH}_{3}\right)$ are readily dispersed in a polypropylene melt and improve stiffness and strength of carbon/polypropylene melt compounds with increasing carbon content at the expense of reduced elongation at break. However, at $10 \mathrm{wt} \%$ carbon content only in the presence of PP$g$-MA, which grafts onto AMFG(Ar/ $\left./ \mathrm{NH}_{3}\right)$, this loss of elongation at break is markedly reduced. This twostage mechanochemical route to AMFG(Ar/ $\left.\mathrm{NH}_{3}\right)$ holds great promise for tailoring other multifunctional nanofillers for producing new families of carbon/ polymer composites as well as carbon dispersions and their use in corrosions resistant coatings.

\section{Acknowledgements}

The authors gratefully acknowledge financial support by the European Community as part of the EU Graphene Flagship (GAN 696656). The authors thank also Dr. R. Feher of AMG Mining for the supply of natural graphite. Furthermore, the authors would like to thank M. Beckert for his great support in the experimental work, R. Merz for XPS analysis, A. Siegel for elemental analysis and A. Warmbold for BET and DSC measurements.

\section{References}

[1] Novoselov K. S., Fal'ko V. I., Colombo L., Gellert P. R., Schwab M. G., Kim K.: A roadmap for graphene. Nature, 490, 192-200 (2012).

https://doi.org/10.1038/nature11458

[2] Appel A-K., Thomann R., Mülhaupt R.: Polyurethane nanocomposites prepared from solvent-free stable dispersions of functionalized graphene nanosheets in polyols. Polymer, 53, 4931-4939 (2012).

https://doi.org/10.1016/j.polymer.2012.09.016

[3] Lee C., Wei X., Kysar J. W., Hone J.: Measurement of the elastic properties and intrinsic strength of monolayer graphene. Science, 321, 385-388 (2008).

https://doi.org/10.1126/science.1157996
[4] Gómez-Navarro C., Burghard M., Kern K.: Elastic properties of chemically derived single graphene sheets. Nano Letters, 8, 2045-2049 (2008).

https://doi.org/10.1021/n1801384y

[5] Krupka J., Strupinski W.: Measurements of the sheet resistance and conductivity of thin epitaxial graphene and SiC films. Applied Physics Letters, 96, 82101/182101/3 (2010).

https://doi.org/10.1063/1.3327334

[6] Schwamb T., Burg B. R., Schirmer N. C., Poulikakos D.: An electrical method for the measurement of the thermal and electrical conductivity of reduced graphene oxide nanostructures. Nanotechnology, 20, 405704/1405704/5 (2009).

https://doi.org/10.1088/0957-4484/20/40/405704

[7] Balandin A. A., Ghosh S., Bao W., Calizo I., Teweldebrhan D., Miao F., Lau C. N.: Superior thermal conductivity of single-layer graphene. Nano Letters, 8, 902907 (2008).

https://doi.org/10.1021/n10731872

[8] Boehm H. P., Clauss A., Fischer G. O., Hofmann U.: Das Adsorptionsverhalten sehr dünner KohlenstoffFolien (in German). Zeitschrift für anorganische und allgemeine Chemie, 316, 119-127 (1962).

https://doi.org/10.1002/zaac.19623160303

[9] Layek R. K., Nandi A. K.: A review on synthesis and properties of polymer functionalized graphene. Polymer, 54, 5087-5103 (2013).

https://doi.org/10.1016/j.polymer.2013.06.027

[10] Potts J. R., Dreyer D. R., Bielawski C. W., Ruoff R. S.: Graphene-based polymer nanocomposites. Polymer, 52, 5-25 (2011). https://doi.org/10.1016/j.polymer.2010.11.042

[11] Bottari G., Herranz M. Á., Wibmer L., Volland M., Rodríguez-Pérez L., Guldi D. M., Hirsch A., Martín N., D'Souza F., Torres T.: Chemical functionalization and characterization of graphene-based materials. Chemical Society Reviews, 46, 4464-4500 (2017). https://doi.org/10.1039/c7cs00229g

[12] Georgakilas V., Otyepka M., Bourlinos A. B., Chandra V., Kim N., Kemp K. C., Hobza P., Zboril R., Kim K. S.: Functionalization of graphene: Covalent and non-covalent approaches, derivatives and applications. Chemical Reviews, 112, 6156-6214 (2012). https://doi.org/10.1021/cr3000412

[13] Liu J., Ye Y., Xue Y., Xie X., Mai Y-W.: Recent advances in covalent functionalization of carbon nanomaterials with polymers: Strategies and perspectives. Journal of Polymer Science Part A: Polymer Chemistry, 55, 622-631 (2017). https://doi.org/10.1002/pola.28426 
[14] Ferrari A. C., Bonaccorso F., Fal'ko V., Novoselov K. S., Roche S., Bøggild P., Borini S., Koppens F. H. L., Palermo V., Pugno N., Garrido J. A., Sordan R., Bianco A., Ballerini L., Prato M., Lidorikis E., Kivioja J., Marinelli C., Ryhänen T., Morpurgo A., Coleman J. N., Nicolosi V., Colombo L., Fert A., Garcia-Hernandez M., Bachtold A., Schneider G. F., Guinea F., Dekker C., Barbone M., Sun Z., Galiotis C., Grigorenko A. N., Konstantatos G., Kis A., Katsnelson M., Vandersypen L., Loiseau A., Morandi V., Neumaier D., Treossi E., Pellegrini V., Polini M., Tredicucci A., Williams G. M., Hong B. H., Ahn J-H., Kim J. M., Zirath H., van Wees B. J., van der Zant H., Occhipinti L., Di Matteo A., Kinloch I. A., Seyller T., Quesnel E., Feng X., Teo K., Rupesinghe N., Hakonen P., Neil S. R. T., Tannock Q., Löfwander T., Kinaret J.: Science and technology roadmap for graphene, related two-dimensional crystals, and hybrid systems. Nanoscale, 7, 4598-4810 (2015). https://doi.org/10.1039/c4nr01600a

[15] Compton O. C., Nguyen S. T.: Graphene oxide, highly reduced graphene oxide, and graphene. Versatile building blocks for carbon-based materials. Small, 6, 711723 (2010).

https://doi.org/10.1002/smll.200901934

[16] Schniepp H. C., Li J-L., McAllister M. J., Sai H., Herrera-Alonso M., Adamson D. H., Prud'homme R. K., Car R., Saville D. A., Aksay I. A.: Functionalized single graphene sheets derived from splitting graphite oxide. The Journal of Physical Chemistry. B, 110, 8535-8539 (2006).

https://doi.org/10.1021/jp060936f

[17] Tölle F. J., Fabritius M., Mülhaupt R.: Emulsifier-free graphene dispersions with high graphene content for printed electronics and freestanding graphene films. Advanced Functional Materials, 22, 1136-1144 (2012). https://doi.org/10.1002/adfm.201102888

[18] Aguilar-Bolados H., Vargas-Astudillo D., Yazdani-Pedram M., Acosta-Villavicencio G., Fuentealba P., Contreras-Cid A., Verdejo R., López-Manchado M. A.: Facile and scalable one-step method for amination of graphene using Leuckart reaction. Chemistry of Materials, 29, 6698-6705 (2017).

https://doi.org/10.1021/acs.chemmater.7b01438

[19] Chua C. K., Sofer Z., Luxa J., Pumera M.: Selective nitrogen functionalization of graphene by Bucherer-type reaction. Chemistry, 21, 8090-8095 (2015). https://doi.org/10.1002/chem.201405748

[20] Wang B., Luo B., Liang M., Wang A., Wang J., Fang Y., Chang Y., Zhi L.: Chemical amination of graphene oxides and their extraordinary properties in the detection of lead ions. Nanoscale, 3, 5059-5066 (2011). https://doi.org/10.1039/c1nr10901d

[21] Qin H., Hwand T., Ahn C., Kim J. A., Jin Y., Cho Y., Shin C., Kim T.: Chemical amination via cycloaddition of graphene for use in a glucose sensor. Nanoscience and Nanotechnology, 16, 5034-5037 (2016). https://doi.org/10.1166/jnn.2016.12231
[22] Jeon I-Y., Shin Y-R., Sohn G-J., Choi H-J., Bae S-Y., Mahmood J., Jung S-M., Seo J-M., Kim M-J., Chang W. D., Dai L., Baek J-B.: Edge-carboxylated graphene nanosheets via ball milling. Proceedings of the National Academy of Sciences of the United States of America, 109, 5588-5593 (2012).

https://doi.org/10.1073/pnas.1116897109

[23] Lu M., Tian Y., Yang Y.: A comparison of electrochemical performance of natural graphite sulfurized by ballmilling and heat-treating as an anode for lithium ion batteries. Electrochimica Acta, 54, 6792-6796 (2009). https://doi.org/10.1016/j.electacta.2009.06.079

[24] Smith C. I., Miyaoka H., Ichikawa T., Jones M. O., Harmer J., Ishida W., Edwards P. P., Kojima Y., Fuji H.: Electron spin resonance investigation of hydrogen absorption in ball-milled graphite. The Journal of Physical Chemistry C, 113, 5409-5416 (2009).

https://doi.org/10.1021/jp809902r

[25] Welham N., Berbenni V., Chapman P.: Effect of extended ball milling on graphite. Journal of Alloys and Compounds, 349, 255-263 (2003). https://doi.org/10.1016/S0925-8388(02)00880-0

[26] Chen X. H., Yang H. S., Wu G. T., Wang M., Deng F. M., Zhang X. B., Peng J. C., Li W. Z.: Generation of curved or closed-shell carbon nanostructures by ballmilling of graphite. Journal of Crystal Growth, 218, 5761 (2000). https://doi.org/10.1016/S0022-0248(00)00486-3

[27] Chen Y. Z., Herz A., Li Y. J., Borchers C., Choi P., Raabe D., Kirchheim R.: Nanocrystalline Fe-C alloys produced by ball milling of iron and graphite. Acta Materialia, 61, 3172-3185 (2013). https://doi.org/10.1016/j.actamat.2013.02.006

[28] Jeon I-Y., Bae S-Y., Seo J-M., Baek J-B.: Scalable production of edge-functionalized graphene nanoplatelets via mechanochemical ball-milling. Advanced Functional Materials, 25, 6961-6975 (2015). https://doi.org/10.1002/adfm.201502214

[29] Zhao W., Fang M., Wu F., Wu H., Wang L., Chen G.: Preparation of graphene by exfoliation of graphite using wet ball milling. Journal of Materials Chemistry, 20, 5817-5819 (2010). https://doi.org/10.1039/c0jm01354d

[30] Kun P., Wéber F., Balázsi C.: Preparation and examination of multilayer graphene nanosheets by exfoliation of graphite in high efficient attritor mill. Central European Journal of Chemistry, 9, 47-51 (2011). https://doi.org/10.2478/s11532-010-0137-5

[31] Hernandez Y., Nicolosi V., Lotya M., Blighe F. M., Sun Z., De S., McGovern I. T., Holland B., Byrne M., Gun'Ko Y. K., Boland J. J., Niraj P., Duesberg G., Krishnamurthy S., Goodhue R., Hutchison J., Scardaci V., Ferrari A. C., Coleman J. N.: High-yield production of graphene by liquid-phase exfoliation of graphite. Nature Nanotechnology, 3, 563-568 (2008). https://doi.org/10.1038/nnano.2008.215 
[32] Knieke C., Berger A., Voigt M., Taylor R. N. K., Röhrl J., Peukert W.: Scalable production of graphene sheets by mechanical delamination. Carbon, 48, 3196-3204 (2010). https://doi.org/10.1016/j.carbon.2010.05.003

[33] Jeon I-Y., Choi H-J., Jung S-M., Seo J-M., Kim M-J., Dai L., Baek J-B.: Large-scale production of edge-selectively functionalized graphene nanoplatelets via ball milling and their use as metal-free electrocatalysts for oxygen reduction reaction. Journal of the American Chemical Society, 135, 1386-1393 (2013). https://doi.org/10.1021/ja3091643

[34] Jeon I-Y., Choi H-J., Ju M. J., Choi I. T., Lim K., Ko J., Kim H. K., Kim J. C., Lee J-J., Shin D., Jung S-M., Seo J-M., Kim M-J., Park N., Dai L., Baek J-B.: Direct nitrogen fixation at the edges of graphene nanoplatelets as efficient electrocatalysts for energy conversion. Scientific Reports, 3, 2260/1-2260/7 (2013).

https://doi.org/10.1038/srep02260

[35] Kim M-J., Jeon I-Y., Seo J-M., Dai L., Baek J-B.: Graphene phosphonic acid as an efficient flame retardant. ACS Nano, 8, 2820-2825 (2014). https://doi.org/10.1021/nn4066395

[36] Jeon I-Y., Zhang S., Zhang L., Choi H-J., Seo J-M., Xia Z., Dai L., Baek J-B.: Edge-selectively sulfurized graphene nanoplatelets as efficient metal-free electrocatalysts for oxygen reduction reaction: The electron spin effect. Advanced Materials, 25, 6138-6145 (2013). https://doi.org/10.1002/adma.201302753

[37] Beckert F., Trenkle S., Thomann R., Mülhaupt R.: Mechanochemical route to functionalized graphene and carbon nanofillers for graphene/SBR nanocomposites. Macromolecular Materials and Engineering, 299, 1513 1520 (2014).

https://doi.org/10.1002/mame.201400205

[38] Ryu S. H., Shanmugharaj A. M.: Influence of long-chain alkylamine-modified graphene oxide on the crystallization, mechanical and electrical properties of isotactic polypropylene nanocomposites. Chemical Engineering Journal, 244, 552-560 (2014).

https://doi.org/10.1016/j.cej.2014.01.101

[39] Yuan B., Bao C., Song L., Hong N., Liew K. M., Hu Y.: Preparation of functionalized graphene oxide/polypropylene nanocomposite with significantly improved thermal stability and studies on the crystallization behavior and mechanical properties. Chemical Engineering Journal, 237, 411-420 (2014).

https://doi.org/10.1016/j.cej.2013.10.030

[40] Blöchl P. E.: Projector augmented-wave method. Physical Review B, 50, 17953-17979 (1994).

https://doi.org/10.1103/PhysRevB.50.17953

[41] Mortensen J. J., Hansen L. B., Jacobsen K. W.: Realspace grid implementation of the projector augmented wave method. Physical Review B, 71, 35109/1-35109/11 (2005).

https://doi.org/10.1103/PhysRevB.71.035109
[42] Enkovaara J., Rostgaard C., Mortensen J. J., Chen J., Dułak M., Ferrighi L., Gavnholt J., Glinsvad C., Haikola V., Hansen H. A., Kristoffersen H. H., Kuisma M., Larsen A. H., Lehtovaara L., Ljungberg M., LopezAcevedo O., Moses P. G., Ojanen J., Olsen T., Petzold V., Romero N. A., Stausholm-Møller J., Strange M., Tritsaris G. A., Vanin M., Walter M., Hammer B., Häkkinen H., Madsen G. K. H., Nieminen R. M., Nørskov J. K., Puska M., Rantala T. T., Schiøtz J., Thygesen K. S., Jacobsen K. W.: Electronic structure calculations with GPAW. A real-space implementation of the projector augmented-wave method. Journal of Physics: Condensed Matter, 22, 253202/1-253202/24 (2010).

https://doi.org/10.1088/0953-8984/22/25/253202

[43] Perdew J. P., Burke K., Ernzerhof M.: Generalized gradient approximation made simple. Physical Review Letters, 77, 3865-3868 (1996). https://doi.org/10.1103/PhysRevLett.77.3865

[44] Lee K., Murray É. D., Kong L., Lundqvist B. I., Langreth D. C.: Higher-accuracy van der Waals density functional. Physical Review B, 82, 81101/1-81101/4 (2010). https://doi.org/10.1103/PhysRevB.82.081101

[45] Xing T., Mateti S., Li L. H., Ma F., Du A., Gogotsi Y., Chen Y.: Gas protection of two-dimensional nanomaterials from high-energy impacts. Scientific Reports, 6 , 35532/1-35532/9 (2016).

https://doi.org/10.1038/srep35532

[46] Beamson G., Briggs D.: High resolution XPS of organic polymers: The Scienta ESCA 300 database. Wiley, Chichester (1992).

[47] Graf N., Yegen E., Gross T., Lippitz A., Weigel W., Krakert S., Terfort A., Unger W. E. S.: XPS and NEXAFS studies of aliphatic and aromatic amine species on functionalized surfaces. Surface Science, 603, 2849-2860 (2009).

https://doi.org/10.1016/j.susc.2009.07.029

[48] Monkhorst H. J., Pack J. D.: Special points for Brillouin-zone integrations. Physical Review B, 13, 51885192 (1976).

https://doi.org/10.1103/PhysRevB.13.5188

[49] Wang Z., Ratvik A. P., Grande T., Selbach S. M.: Diffusion of alkali metals in the first stage graphite intercalation compounds by vdW-DFT calculations. RSC Advances, 5, 15985-15992 (2015). https://doi.org/10.1039/C4RA15529G

[50] Wang J., Sorescu D. C., Jeon S., Belianinov A., Kalinin S. V., Baddorf A. P., Maksymovych P.: Atomic intercalation to measure adhesion of graphene on graphite. Nature Communications, 7, 13263/1-13263/7 (2016). https://doi.org/10.1038/ncomms 13263

[51] Chattopadhyay P. P., Manna I., Talapatra S., Pabi S. K.: A mathematical analysis of milling mechanics in a planetary ball mill. Materials Chemistry and Physics, 68, 85-94 (2001). https://doi.org/10.1016/S0254-0584(00)00289-3 
[52] Urakaev F. K., Boldyrev V. V.: Mechanism and kinetics of mechanochemical processes in comminuting devices: 1. Theory. Powder Technology, 107, 93-107 (2000). https://doi.org/10.1016/S0032-5910(99)00175-8
[53] Hofmann D., Wartig K-A., Thomann R., Dittrich B., Schartel B., Mülhaupt R.: Functionalized graphene and carbon materials as additives for melt-extruded flame retardant polypropylene. Macromolecular Materials and Engineering, 298, 1322-1334 (2013).

https://doi.org/10.1002/mame.201200433 